\title{
Contribution of Risk Factors for Infrastructure Development of Nepal
}

\author{
Madhav Prasad Koirala \\ Department of Civil and Architect, Member of Subject Committee, Pokhara University, Pokhara, Nepal
}

\section{Email address:}

madhavkoirala9@gmail.com

\section{To cite this article:}

Madhav Prasad Koirala. Contribution of Risk Factors for Infrastructure Development of Nepal. American Journal of Civil Engineering. Vol. 5, No. 3, 2017, pp. 124-131. doi: 10.11648/j.ajce.20170503.11

Received: January 12, 2017; Accepted: January 25, 2017; Published: March 14, 2017

\begin{abstract}
All most all infrastructure projects are being over running in terms of either time or amount and even deteriorated the quality of the projects. For new professionals and the experts are learning bad train which must be stop it as soon as possible. This is because of contributed risk factors, No body, either government agency of Nepal take care about this risk factors or from public, the infrastructure projects which are losing a lot every minute, quality and money. This research explores to analyze, and mitigate the understanding of risk management in the infrastructures development projects. Deeper understanding by means of detailed study during pre-planning and planning phase is expected to enhance more effective risk management and, therefore, a better productivity and better quality to be achieved, which creates the satisfactions to all stakeholders.
\end{abstract}

Keywords: Risk Factors, Infrastructures, Development, GDP, Household

\section{Introduction}

Nepal is one of the developing countries and for more than one decade, suffered from the civil insurgency, now it is on the peace process which is not yet concluded. It is landlocked country which is situated between China and India. In the infrastructures development either in rural area or urban area, professional consciousness was must. Previous performed infrastructures were not properly planed so that could not became result oriented. Although first five year development plan from 1956, its economic plan was started and now already passed tenth five year plan and could not get success as per the objective.

It is difficult for a new professional to identify new risks, in a new environment and politically instable country like Nepal. It is more difficult to assess these risks and impact of relationships among them. Legal policy framework has not made by the government because of frequently changing government and hence legal and political risk factors are playing great role for equitable urban development. Financial and economic is other risk factor. It is more difficult to assess these risks and impact of relationships among them. The trend in Nepalese projects is just ignoring and making the decision of unrealistic and irresponsible by authorized professionals and other fact is identifying analyzing new risks becoming complicated, expensive and time consuming due to omitting the risks management plan during planning phase [7].

\subsection{Beginning}

Construction project is an important industry that can contribute to the nation for develop the infrastructures. In recent days lot of construction firms and labors are hiring from others countries similarly, the construction firms from our country are working to others countries. The construction companies who are working in our country are importing, machineries, raw materials even that the raw materials are producing in this country. This means we are losing huge inland revenue for the country.

\subsection{Ending}

Infrastructure development in developed countries are also not yet enough developed either sustainable development or environment pollution point of view with many more problems which are quite different to compare to developing countries. To execute the urban development, first need to well plan with breaking down even small activates and another important 
phase is execution which needs to concentrate more effect. Effective technical team with experienced and skilled team leader needed with organization and then only risk may identify, analysis, response and taking care.

\section{Problems}

Infrastructure projects are not implemented as estimated time, amount and quality in Nepal. This train is increasing order which is being common in all public. This is very unethical and unfair for young and expert professionals.

\section{Objective of the Research}

The objective the research is explore the problems based on the different case studies of the infrastructures.

\section{Limitation of the Research}

The limitation of this research is valid in similar infrastructure in Nepal and cannot generalized to other infrastructures all over the world.

At present, only about $72 \%$ of the country's population has access to basic water supply. Moreover, most of the urban water supply systems are not delivering an efficient and effective service. In the rural areas, the government policy has been handed over the management of the Department of Water Supply and Sewerage (DWSS) built systems to the concerned communities. In spite of this, many rural water schemes are not functioning properly. So, currently, the government is planning to rehabilitate and upgrade more than 500 such schemes and hand them over to the concerned communities for operation and maintenance (O\&M). The sanitation sector too is lagging far behind in Nepal. In fact, only $25 \%$ of the whole population has sanitation facility. Even the few sewerage systems in existence/ operation are not functioning satisfactorily. At present, the water supply and the sanitation programs have been tied up together. As a result, things are gradually improving in the latter. Public health education programs are also being integrated with the drinking water and sanitation programs. For water supply and sanitation, the National Water Plan 2005 targets [14].

Irrigation is a major factor in the development of Nepal. It is the largest water use sub-sector, affects the life of many people involved in agriculture, the major contributor (40\%) to the Gross Domestic Product and a major factor for maintaining food security in the country. The government, from the very beginning, has wisely recognized this fact and given due importance to irrigation, both in its yearly and five year plans. In the $10^{\text {th }}$ five-year plan $(2002-2007), 9.7 \%$ of the total national development budget was allocated to irrigation. Given the importance of irrigation and the large investments already made and planned for the future, the effectiveness of water delivery and its ultimate sustainability are of major concern [14].

Project management is the discipline of planning, organizing, securing and managing resources to bring about the successful completion of specific engineering project goals and objectives [4].

\section{Method and Discussion of Study}

This study is carried out base on research materials and the case study raised in the infrastructure projects site as discussed below.

(a) Construction Project Management (CPM) is a technicaloriented service for construction project clients. Evaluating the performance of service providers is beneficial both to purchasers, enabling them to appraise the services received, and to providers, helping them to improve their services. However, no appraisal system for such services exists. This study developed a novel customer satisfaction evaluation model for CPM services that was developed using a questionnaire-based survey and statistical analysis. Test results show that the developed model is a feasible system [15].

Construction projects involve multistakeholders (e.g., architects, structural engineers, surveyors, contractors, suppliers, etc. completing a large number of unpredictable tasks in a complex process within a limited period of time. Construction project managers) C-PMs are the key persons in achieving project success throughout the construction process, as they are responsible for planning the construction program, organizing human resources, controlling operations and the budget, and forecasting probable difficulties. Hence, C-PMs always encounter a great deal of stress in construction projects. Apart from the subjective feelings experienced by individual C-PMs, C-PMs may also feel objective stress due to the deviation between their actual abilities and their expected abilities on tasks or projects [8].

Many jobs that are part of the project management construction project feature elements of administrative work, but they are too critical to the project to be correctly called anything other than the project manager's job. Here are a few examples of this type of project management work:

Table 1. Contribution to the GDP.

\begin{tabular}{|c|c|c|c|c|c|c|c|c|c|c|c|}
\hline Year & $99 / 00$ & $00 / 01$ & $01 / 02$ & $02 / 03$ & $03 / 04$ & $04 / 05$ & $05 / 06$ & 06/07 & $07 / 08$ & $08 / 09$ & $09 / 10$ \\
\hline Percentage of total GDP & 10.50 & 6.50 & 7.25 & 7.25 & 7.0 & 7.0 & 7.25 & 7.0 & 7.60 & 7.50 & 7.00 \\
\hline
\end{tabular}

The professions are defined largely around their area of distinctive competence. The project management BOKs (Bodies of Knowledge) are an attempt to map out the knowledge elements of this competence. Project management BOKs are clearly important. Practitioners have a strong interest in them since such 'standards' - which is de facto what they essentially become - influence industry views on competence, best practice, and training and development. And they are of interest to academics since any such attempt to define the 'discrete body of knowledge and related skills' 
raises questions about the validity of the knowledge base in the subject being discussed or taught, both in epistemological terms and in terms of what is deemed to be covered by the subject area. Drafting a formal Body of Knowledge brings with it risks. Not least are those of scope and relevance; not recognizing the real scope of the discipline can lead, as we have seen, to misperceptions on a significant scale. Overemphasis on didactic methodology suggesting the rote application of best practices diminishes the role of judgment that managers need in applying knowledge in different contexts. The subject requires a more interpretive approach, particularly with respect to the broader, more strategic elements of knowledge which feature at the more front-end, senior, and program levels of the 'management of projects' job family. Positioning the profession, and its bodies of knowledge, in this bigger domain, is the challenge now in rethinking and re-casting project management. Research has an important role to play in this re-positioning. Though the dimensions of the profession have, so far, largely been driven by practitioners, researchers should have the advantage of time, data and argument. They teach. They influence. They serve on the professions' panels. The time is ripe for a more systematic input from the academic research community, not least to address the points articulated in this paper. If we rely on the project management associations to tell the academics what to think and teach, instead of having research test the concepts theoretically and the issues practically, we get into self-fulfilling prophecies. We may be in some danger of that now. Several lines of research [10].

According to A report prepared for the International Labour
Organization ILO Country office for Nepal, infrastructure contribution to the GDP, and employment During the 1990s, construction sector attained high growth and grew at a substantially higher rate compared to overall GDP. However, growth rate declined sharply during the 2000s in absolute terms as well as in relation to GDP. During 1990/91 to $1999 / 2000$, the sector grew at an annual rate of 6.27 per cent per annum while GDP grew at 4.73 per annum. The respective growth rates were 3.56 and 3.51 per cent during 2000/01 to 2010/11. Thus, construction sector can no longer be said to be pulling overall economic growth in the country [11].

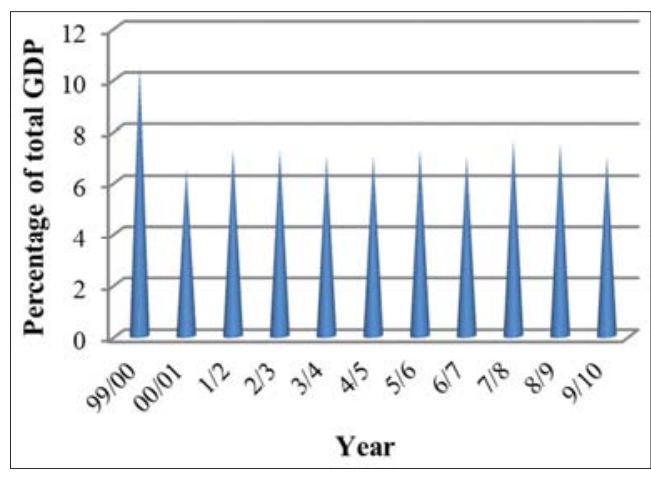

Source: [11]

Figure 1. Percentage of total GDP.

As per annual Household survey 2012 / 13, Housing status in urban and rural has been described in detail. in the following table it is given in detailed.

Table 2. Percentage distribution of households by occupancy status.

\begin{tabular}{|c|c|c|c|c|c|}
\hline Urban/rural & Owner & Renter & Rent free & Others & Total \\
\hline Urban & 57.5 & 38.8 & 3.4 & 0.4 & 100.0 \\
\hline Rural & 94.1 & 3.6 & 2.0 & 0.4 & 100.0 \\
\hline \multicolumn{6}{|c|}{ Consumption quintiles } \\
\hline Lowest (First) & 95.6 & 0.9 & 2.8 & 0.8 & 100.0 \\
\hline Second & 96.0 & 2.0 & 2.0 & 0.0 & 100.0 \\
\hline Middle & 94.6 & 3.0 & 1.9 & 0.6 & 100.0 \\
\hline Fourth & 87.7 & 9.5 & 2.8 & 0.0 & 100.0 \\
\hline Nepal & 87.2 & 10.2 & 2.3 & 0.4 & 100.0 \\
\hline
\end{tabular}

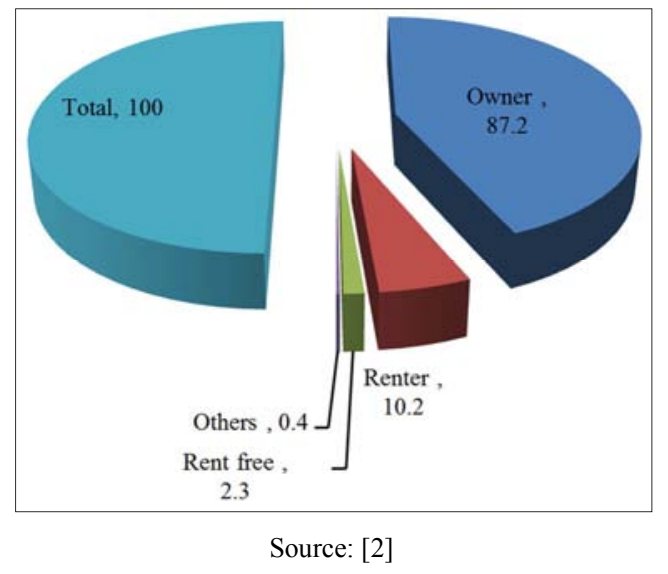

Figure 2. Percentage distribution of households by occupancy status.
Housing to people is challenging work in all over the country even it is being one parameter of development indicator. Due to devastation earthquake rebuild is another job in Nepal. It is very risky work to recover and build the house all over the country.

(b). What is risk?

Al-Bahar (1998) has also tried to define risks as the exposure to the "chance of occurrences of events adversely or favorably affecting project objective as a consequence of uncertainty" In the same way [15] has defined " risk in housing and real estate in construction projects are the chances of occurrences of events which affect the objectives and hence it will lost the productivity within the project life cycle." Risks are unexpected events or circumstances that have a chance of occurring and that may prevent a project from meeting its schedule and cost estimate or budget. 
Risk Management is defined as a formal orderly process for systematically identifying, analyzing and responding to risk events throughout the life of a project to obtain optimum degree of risk elimination or control [1]. Risk management is a scientific approach of identifying, anticipating and minimizing the possible adverse impacts on the projects. 'The only permanent solution in which risk identification, risk analysis, risk ranking, and risk response plan can give the integrated package [8].'

\section{(c) Risk Identification}

It determines which risks might affect the construction project and documents their inheriting characteristics. Authority or delegate in risk identification activities can include the following, where appropriate project manager, project team members, risk management team, subject matter experts from outside the project team, customers, end users, other project managers, stakeholders, and risk management experts. While these personnel are often key participants for risk identification, all project personnel should be encouraged to identify risks. Risk Identification is an iterative process because new risks may become known as the project progresses through its life cycle. The frequency of iteration and who participates in each cycle will vary from case to case. The project team should be involved in the process so that they can develop and maintain a sense of ownership of, and responsibility for, the risks and associated risk response actions. Stakeholders outside the project team may provide additional objective information. The Risk Identification process usually leads to the Qualitative Risk Analysis process. Alternatively, it can lead directly to the Quantitative Risk Analysis process when conducted by an experienced risk manager. On some occasions, simply the identification of a risk may suggest its response, and these should be recorded for further analysis and implementation in the Risk Response Planning process.

\section{Risk Identification: Inputs}

(i) Environmental Factors: Available information, including commercial databases, academic research or studies, benchmarking, or other available industry studies or report, may also be useful in identifying risks. (ii) Organizational Process Assets: Data and information received on prior projects may be available from previous project files or sources, including actual data and lessons learned. (iii) Project Scope Statement: Project assumptions are found in the project scope statement Uncertainty in project assumptions should be evaluated as potential causes of project risk. (iv) Risk Management Plan: Key inputs from the risk management plan to the Risk Identification process are the assignments of roles and responsibilities, provision for risk management activities in the budget and schedule, and categories of risk which are sometimes expressed in an RBS. (v) Project Management Plan: The Risk Identification process also requires an understanding of the schedule, cost, and quality management plans found in the project management plan Outputs of other Knowledge Area processes should be reviewed to identify possible risks across the entire project.

\section{J. Risk Identification: (i) Tools and Techniques}

Documentation Reviews: A structured review may be performed of project documentation, including plans, assumptions, prior project files, and other information. The quality of the plans, as well as consistency between those plans and with the project requirements and assumptions, can be indicators of risk in the project.

(ii) Information Gathering Techniques: Examples of information gathering techniques used in identifying risk can include:

(iii) Brainstorming: The goal of brainstorming is to obtain a comprehensive list of project risks. The project team usually performs brainstorming, often with a multidisciplinary set of experts not on the team. Ideas about project risk are generated under the leadership of a facilitator. Categories of risk, such as a risk breakdown structure, can be used as a framework. Risks are then identified and categorized by type of risk and their definitions are sharpened. (iv) Delphi technique: The Delphi technique is a way to reach a consensus of experts. Project risk experts participate in this technique anonymously. A facilitator uses a questionnaire to solicit ideas about the important project risks. The responses are summarized and are then recirculated to the experts for further comment. Consensus may be reached in a few rounds of this process. The Delphi technique helps reduce bias in the data and keeps any one person from having undue influence on the outcome. (v) Interviewing: Interviewing experienced project participants, stakeholders, and subject matter experts can identify risks. Interviews are one of the main sources of risk identification data gathering. (vi) Root cause identification: This is an inquiry into the essential causes of a project's risks. It sharpens the definition of the risk and allows grouping risks by causes. Effective risk responses can be developed if the root cause of the risk is addressed. (vii) Strengths, weaknesses, opportunities, and threats (SWOT) analysis: This technique ensures examination of the project from each of the SWOT perspectives, to increase the breadth of considered risks.

(viii) Checklist Analysis: Risk identification checklists can be developed based on historical information and knowledge that has been accumulated from previous similar projects and from other sources of information. The lowest level of the RBS can also be used as a risk checklist. While a checklist can be quick and simple, it is impossible to build an exhaustive one. Care should be taken to explore items that do not appear on the checklist. The checklist should be reviewed during project closure to improve it for use on future projects. (ix) Assumptions Analysis: Every project is conceived and developed based on a set of hypotheses, scenarios, or assumptions. Assumptions analysis is a tool that explores the validity of assumptions as they apply to the project. It identifies risks to the project from inaccuracy, inconsistency, or incompleteness of assumptions. (x) Diagramming Techniques: Risk diagramming techniques may include:

(xi) Cause-and-effect diagrams- These are also known as 
Ishikawa or fishbone diagrams, and are useful for identifying causes of risks. (xii) System or process flow charts-These show how various elements of a system interrelate, and the mechanism of causation. (xiii) Influence diagrams- These are graphical representations of situations showing causal influences, time ordering of events, and other relationships among variables and outcomes. Risk Identification: OutputsThe outputs from Risk Identification are typically contained in a document that can be called a risk register.

II Risk Register: The primary outputs from Risk Identification are the initial entries into the risk register, which becomes a component of the project management plan. The risk register ultimately contains the outcomes of the other risk management processes as they are conducted. The preparation of the risk register begins in the Risk Identification process with the following information, and then becomes available to other project management and Project Risk Management processes.

(i) List of identified risks: The identified risks, including their root causes and uncertain project assumptions, are described. Risks can cover nearly any topic, but a few examples include the following: A few large items with long lead times are on critical path. There could be a risk that industrial relations disputes at the ports will delay the delivery and, subsequently, delay completion of the construction phase. Another example is a project management plan that assumes a staff size of ten, but there are only six resources available. The lack of resources could impact the time required to complete the work and the activities would be late. (ii) List of potential responsesPotential responses to a risk may be identified during the Risk Identification process. These responses, if identified, may be useful as inputs to the Risk Response Planning process. (iii) Root causes of risk- These are the fundamental conditions or events that may give rise to the identified risk. (iv) Updated risk categories- The process of identifying risks can lead to new risk categories being added to the list of risk categories. The RBS developed in the Risk Management Planning process may have to be enhanced or amended, based on the outcomes of the Risk Identification process. In construction projects, many parties are involved such as owner, consultant, contractor, sub-contractor, and supplier etc which is known as the team. Each party has its own risks. In Nepalese construction projects, it is not found about the research of particularly the identification and management of risks. We can found in world's construction projects are suffering risks. Consequently, it is significant to have a research about the risks that owners have to face in their financial investment in construction projects and the way they managed their risks as well as how to control construction risks smoothly because they are one of the most important teams that are involved in the projects from the beginning until completion and handed over. The following are important risks in which construction teams are facing as follows.

(A) Political Risk

Nepal is fertile land to obstruct in the name of politics.
Political risks are beginning when project get conceptualize. Planning Commission who makes the plan itself is influenced by the political party. Similarly, strike, closed, donation to political party, interference by the political parties, disturbance due to different issues as mentioned above, confidentiality of political parties and permits and licenses delay due to political instability ect are main issues of political risks.

Political risks are a bundle of distinct risks that can include not only political factors but also administrative, social and economic factors. Political risks associated with a project are closely evaluated as they are generally outside the control of the parties to the project, other than the government to a certain extent. But even the government fixing the policies of the telecom industry does not have control over all the categories of political risks. It should be kept in mind that many of the political risks arise from the possibility of arbitrary action by the government and altering the framework on which the very foundation of the project rests. The main categories of political risks include (i) Risk of political instability such as riots, revolutions, coup, terrorism, guerrilla warfare (ii) War, whether declared or undeclared. (iii) International sanctions (iv) Expropriation (v) Nationalization (vi) Creeping expropriation (discretionary regimes, excessive taxation, import restrictions, refusal to allow or provide for collection or review of tariffs, etc) (vii) Failure to grant or renew approvals and (viii) Excessive interference in the implementation of the project, thereby causing severe prejudice to the concessionaire.

(B). Contractual risks

Construction companies and other entities must take contractual risks. Some of those risks are legal risks (For example claims, warranty problems, default terminations, intellectual property infringement charges, alleged confidentiality disclosures, disputes, and litigation) and some are business risks (For example poor relationships, failure to obtain objectives, bad public relations, declining morale, instability, weakening of brand integrity, loss of goodwill, and reduced revenue or profits). We read in news paper, during contract biding period it was observing lot of illegal works like capturing the bidding document, not allowed to bid the good contractors using force, buying and selling before assign the contract ect were facing by the professional good contractor. To remove such incidents, professional contractors were demanded an electronic bidding. Government has relies it and try to introduce it in certain limited department of government authority could not possible to implement in all sectors because of lack of resources. Feedback is coming that some contractors are facing within the department giving and taking is still taking place even in electronic bidding, so professional contractors are not satisfied and they want to improvement in electronic bidding system.

(C). Performance risks

Performance risk can be evaluating of construction projects is essential for ensuring that planned improvements in quality, cost and time are achieved. It helps clients to 
compare achieved performance with that of similar projects, identify potential for doing things better and assess how suppliers compare with other potential suppliers. Customers also need to measure their own performance and benchmark with other customers to identify areas for improvement. Scope, nature and duration of work, Schedule interactions, Size, Safety and environmental performance, Weather, Soil and foundations, External influences and Operator and influences at time of bid.

(D). Financial risks

Financial risk in construction projects includes whether the building owner has enough money to complete the project, financial failure of the Building owner or sub-contractors, availability of money to the contractor in a suitable manner and time to enable the contractor to progress with the work, financial risk also includes adequate provision of cash flow, fluctuations, inflation and taxation. Contractors could financially fail due to dependence on banks and paying high rate, lack of capital, cash flow management, low margin of profit due to competition, principle of award of contract to lowest builder. Among the financial risks project financing can be main factor which lead the project in entire life-cycle. Labor and material costs fluctuation can be other risk during construction project. Earnings volatility leads the construction project other risk. Currency fluctuation can be other risk of the construction project. Interest rate changes will loss by the project due to arrange fund. Commodity price fluctuation, regulatory exposures, funding risks and employee stock options will loss due to managing extra fund.

(E). Technical risks

The risks related to technological problems are familiar to the design/construct professions which have some degree of control over this category. However, because of rapid advances in new technologies which present new problems to designers and constructors, technological risk has become greater in many instances. Certain design assumptions which have served the professions well in the past may become obsolete in dealing with new types of facilities which may have greater complexity or scale or both.

Technical risks are mainly oriented due to pure technical issues. For example engineering designed quality of the project can be one risk, new technology which not adopted or adopted but not operator has not trained can be other risk, Spoil type, strata of the layer will be other type of risk. For example, during the site inspection time we estimated soft soil but there was hard rock in the foundation. This type of risk is technical risk.

(F). Geographical Risks This risk occurs due to the location of the work of its project territory, for example if we take the site of rock cutting lot of risk has to face being life injury maintaining safety measures etc. Similarly if in soft strata, during rainy season there will be chances of land slide which losses lot of effort to maintain the site. In the same way lot of example can be give under the geographical risk.

Site conditions, particularly subsurface conditions which always present some degree of uncertainty, can create an even greater degree of uncertainty for facilities with unknown characteristics during operation. Because construction procedures may not have been fully anticipated, the design may have to be modified after construction has begun. An example of facilities which have encountered such uncertainty is the nuclear power plant, and many owners, designers and contractors have suffered for undertaking such projects.

(G). Operator Risks Operation risk is observing during operation of the construction project. The following are some risks which will be under operation risks.

(H). Organizational Risks the risks related to organizational relationships may appear to be unnecessary but are quite real. Strained relationships may develop between various organizations involved in the design/construct process. When problems occur, discussions often center on responsibilities rather than project needs at a time when the focus should be on solving the problems. Cooperation and communication between the parties are discouraged for fear of the effects of impending litigation. This barrier to communication results from the ill-conceived notion that uncertainties resulting from technological problems can be eliminated by appropriate contract terms. The net result has been an increase in the costs of constructed facilities.

(I). Insurable Risks

Construction insurance is a practice of exchanging a contingent claim for a fixed payment to protect the interests of parties involved in a construction project. Construction insurance is a major method of managing risks in the construction industry. Its primary function is to transfer certain risks from clients, contractors, subcontractors and other parties involved in the construction project to insurers to provide contingent funding in time of difficulty. Construction insurance plays an increasingly important role in guaranteeing the success of projects, with insurers sharing losses resulting from natural disasters and other contingencies. However, insurance sometimes doesn't receive the attention it deserves because practitioners do not have a clear understanding of risk allocation and the strategy of risk management through insurance.

Risks \& Exposures: There are various risks exposeres which are facing at the site and described as below.

(i) Financial Risks \& Exposures Project Financing (Debt, Equity), Labor and Material Costs (FTE's, Contract, Outsourced), Earnings Volatility (Revenue Recognition, EPS Growth), Currency Fluctuation (Foreign Exchange, Arbitrage), Interest Rate Changes (Credit Risks, Bonding), Commodity Price Fluctuations (Options, Derivatives), Regulatory Exposures (IRS, FASB), Funding Risks (Government Contract Funding, Allocations) and Employee Stock Options (Pension Funds, Dividends)

(ii) Contractual Risks \& Exposures Contractual Liability (Breach, Third-Party Actions), Indemnification (Hold Harmless Clauses), Indemnification Forms (Limited, Intermediate and Broad), Design Responsibility (Design Delegation, Assumption of Risk), Warranties (Express, Implied), Waivers of Subrogation, Liquidated, Consequential 
and Punitive Damages Clauses, Force Majeure Clauses (Schedule Delay) and Subcontractor Default

(iii) Operational Risks \& Exposures Operations Failure Risk, Construction Defect, Weather Volatility (Seasonality, Cat Risk), Political Risk (Domestic, International), Reputational Risk (Company, Product/Service Defamation), Regulatory Risk, Operational Leverage Risk, Material / Labor Price Risk and Supplier Provisioning Risk

(iv) Organizational Risks \& Exposures (Project Delivery Methods) General Construction Contracts (Design-BidBuild), Design-Build Contracts (Self-Performed or Subcontracted Design), EPC Contracts (Engineering, Procurement and Construction), Construction Management Contracts (CM At-Risk or Agency CM), Fast Track Contracts

(v) Insurable Risks \& Exposures Workers Compensation and Employers Liability, Commercial General Liability, Commercial Property and Builders Risk, Professional Liability (E\&O Coverage), Environmental Liability (Pollution Coverage), Contractors Professional Liability, Directors and Officers Liability (D\&O Coverage), Employment Practices Liability (EPL), Project Specific Coverage (OCP, RRP, PMPL), Owners and Contractors Protective Liability (OCP), Railroad Protective Liability (RRP), Project Management Protective Liability (PMPL) and Subcontractor Default Liability (Bonding Alternative)

Managing projects within time, cost and performance is easier said than done. As shown in Table $3 \& 4$, time, cost and performance are the main constraints of a project. If the project is executed for an outside customer, then the project has a fourth constraint which is good customer relation or customer friendly. The definition of project success also has been extended or modified to include completion:

Within the allocated time period, Within the budgeted cost, At the proper performance or specification level, With acceptance by the customer/user, When you can use your customer's name as a reference, With minimum or mutually agreed upon scope changes, Without disturbing the main work flow of the organization and Without changing the corporate culture [5].

Contractors are independent business organizations and are awarded the projects to produce the required end product as stipulated in the contract documents. In the case of the owner and the contractor may disagree on certain things, the achievement of the end product must always be the top priority of both parties. A good relationship between owner and the project contractor must be maintained so that the contractor's expertise, labor and equipment can be best utilised to achieve the objectives of the project. The contractor is also required to produce a quality control plan to maintain a job surveillance of its own, to perform tests and keep records to ensure the works conform to the contract requirements. The owner should monitor and supervise the contractor's quality plan and make a sport checks inspection from time to time during the construction process [12].

According to "Arun-III Project: Nepal's Electricity Crisis and its Role in Current Load Shedding and Potential Role 10
Years Hence" in the article of [13] time overrun has described as follows.

Table 3. Time overrun in Nepalese Hydropower Projects.

\begin{tabular}{ll}
\hline Hydropower Projects & Time overrun \\
\hline Kulekhani I & 21 months \\
Marsyangdi & 7 months \\
Kali Gandaki-A & 18 months \\
Chilime & 60 months \\
\hline
\end{tabular}

Source: [13]

As per the source of Nepal Electricity Authority, Kulekhani-III Project is categorized as a National Priority Project (P1) by National Planning Commission, Government of Nepal (GoN). The funds from Government of Nepal and NEA will be utilized for the construction of the Project. The total estimated cost of the Project is NRs 2,334 million. The Project is schedule to be commissioned in FY 2010/11.

As per Kantipur daily newspaper dated march 2, 2011, Kulekhani Third and Chameliya hydropower project need additional 2 years time and extra amount of money to complete the project. Additional Nrs.60 corer has demanded by the contractor "China Gezhouba Water and Power Group Company Limited (CGGC) on December 21, 2006, the Project construction is gaining momentum and the project is scheduled to be completed in year 2011." Similarly, additional Nrs. 80 corer money has demanded by the Sino hydro the contractor of Kulekhani Third The reason of Chameliya shown by contractor is due to weak soil structure and the Kulekhani Third is due to strike, stoppage and not to permit to cut down the trees in the project areas by the authority.

Table 4. Money Over Spent in Hydropower Projects.

\begin{tabular}{lll}
\hline Project & $\begin{array}{l}\text { Estimated Rupees in } \\
\text { million }\end{array}$ & $\begin{array}{l}\text { Additional Rupees } \\
\text { In million }\end{array}$ \\
\hline Kulekhani Third & 2334 & 80 \\
Chameliya & 5752 & 60 \\
\hline
\end{tabular}

Source: [13]

\section{Conclusion}

Based on study of various infrastructure projects either it has exceeding the time or money and even the quality due to improper planning and contributing various risk factors. So in Financial, health related organization use to care about contributed risk factors. But in Infrastructure projects either from the government level or public level the identification, analysis and response of contributing risk factors are not taking into account seriously yet. The research explored the risk factors based on its implication in the projects, analyzed and ranked them based on survey and mitigation of the risk factors in the construction projects according to developers, authorities represented, the professional and experts. Infrastructures sector in Nepalese context, it is facing various adversities, in which this sectors is losing its productivity. Government need to formulate risk taking care by making 
appropriate policy and expert need to raise the issue. In future risk in housing, roads, irrigation construction project need to carry out in the research.

\section{References}

[1] Al-Bahar, J. (1988).'Risk Management Approach for Construction Projects: a systmatic analytical approach for contractor, Ph. D. thesis', University of California, Berkeley, CA.

[2] Annual Household Survey, 2012/13, (2014). Government of Nepal, National Planning Commission secretariat, Central Bureau of statistics, may 2014, Published by Central Bureau of Statistics, Thapathali, Kathmandu, Nepal.

[3] Economy survey. (2010) Minister of Finance, Singadarbar Kathmandu, Nepal.

[4] Hemmati, A. Hemmati, M. and Mohammad (2012). 'The Acquaintance with Organizational Maturity Model of Project Management', Middle-East Journal of Scientific Research 12 (10): 1391-1395, ISSN 1990-9233, IDOSI Publications, DOI: 10.5829/idosi.mejsr.2012.12.10.67, Abhar Branch, Islamic Azad University, Abhar, Iran. 1391.

[5] Kerzner, H. (2001). "Project Management" CBS Publishers \& Distributers, India.

[6] Koirala, M. P. (2014), Risk in housing and real estate Construction Project, Journal of the Institute of Engineering vol-10, No. 1, pp 34-44. TUTA/IOE/PCU.

[7] Koirala, M. P. (2012). Urban Development Projects and risk management in Nepal, Journal of Research \& Innovation (JORI), vol. 1, November 2012, Post Graduate Student society.

[8] Koirala, M. P., (2012). Risk in Housing and Real Estate
Construction Project Study in Nepal. A thesis submitted to the Singhania university, Rajasthan, India, in partial fulfillment of the requirement for the degree of Doctor of Philosophy in Engineering.

[9] Leung, M. y. Chan, Y. S. and Yu, J. (2009). 'Integrated Model for the Stressors and Stresses of Construction Project Managers in Hong Kong', Journal of Construction Engineering and Management, Vol. 135, No. 2, February 1, 2009, ISSN 0733- 9364/2009/2- 126134. DOI: 10.1061/(ASCE)0733- 9364(2009)135: 2 (126).

[10] Morris, P. W. G., Crawford, L. D., Hodgson, Shepherd, M. M. Thomas, J. (2006).'Exploring the role of formal bodies of knowledge in defininga profession - The case of project management', International Journal of Project Management 24 (2006) 710-721, Published by Elsevier Ltd and IPMA., doi: 10.1016/j.ijproman.2006.09.012.

[11] Nepal: Addressing the Employment Challenge, through the Sectoral Pattern of Growth report prepared for the International Labour Organization, ILO Country office for Nepal April 2014, ILO Publications, International Labour Office, CH-1211 Geneva 22, Switzerland., Printed in Nepal.

[12] Oberlender, G. D. (1993).'Project Management For Engineering And Management' McGraw-Hill Inc, New York.

[13] Shrestha, R. S. (2011). The Kantipur Daily, 2 march, Kantipur Publication.

[14] Water Resources of Nepal In The Context of Climate Change. (2011). Water and Energy Commission Secretariat. Singha Durbar, Kathmandu, NepalWebsite: www.wec.gov.np.

[15] Yang, J. B. Peng S. C. (2008). 'Development of a customer satisfaction evaluation model forconstruction project management', Building and Environment 43 458-468, Institute of Construction Management, Chung Hua University, No. 707, Sec. 2, Wu-Fu Rd., Hsinchu 300, Taiwan. 